\title{
Estimating Transportation-Related Greenhouse Gas Emissions in the Port of Busan, S. Korea
}

\author{
Kangwon Shin and Jang-Pyo Cheong ${ }^{1) *}$ \\ Department of Urban Design and Development Engineering, Kyungsung University, Busan, Korea \\ ${ }^{1)}$ Department of Environment Engineering, Kyungsung University, Busan, Korea \\ *Corresponding author. Tel: +82-51-663-4734, E-mail: jpjung@ks.ac.kr
}

\begin{abstract}
The port of Busan is the fifth busiest container port in the world in terms of total mass of 20-foot equivalent units transported. Yet no attempts have been made to estimate the greenhouse gas (GHG) emissions from the port of Busan by accounting for all port-related activities of the various transportation modes. With these challenges in mind, this study estimates the first activity-based GHG emissions inventory in the port of Busan, which consists of four transportation modes: marine vessels, cargo-handling equipment, heavy-duty trucks, and railroad locomotives. The estimation results based on the most recent and complete port-related activity data are as follows. First, the average annual transportation GHG emission in the port of Busan during the analysis period from 2000 to 2007 was $802 \mathrm{Gg} \mathrm{CO}_{2}$-eq, with a lower value of $773 \mathrm{Gg} \mathrm{CO}$-eq and an upper value of $813 \mathrm{Gg} \mathrm{CO}_{2}$-eq. Second, the increase in the transportation-related GHG emissions in the port of Busan during the analysis period can be systematically explained by the amount of cargo handled $\left(R^{2}=\right.$ 0.98). Third, about $64 \%$ of total GHG emissions in the port of Busan were from marine vessels because more than $40 \%$ of all maritime containerized trade flows in the port were transshipment traffic. Fourth, approximately $22 \%$ of the total GHG emissions in the port of Busan were from on-road or railroad vehicles, which transport cargo to and from the port of Busan. Finally, the remaining $14 \%$ of total GHG emissions were from the cargo handling equipment, such as cranes, yard tractors, and reach stackers.
\end{abstract}

Key words: Greenhouse gas emissions, Port-related activities, Climate change, Logistics, Busan port

\section{INTRODUCTION}

The port of Busan is the fifth busiest container port in the world in terms of total mass of 20-foot equiva- lent units (TEU) transported through the port (American Association of Port Authorities, 2008). In addition, the port of Busan is a significant national hub for Korea, through which flows more than $65 \%$ of all Korean maritime containerized trade (Korea Maritime Institute, 2006). Thus, it is imperative to estimate the GHG emissions at this port, which can be used to undertake measureable, reportable, and verifiable (MRV) GHG mitigation actions.

A few studies have attempted to estimate the GHG emissions from the port of Busan. Cheong et al. (2007) reported that about $32 \%$ of all GHG emissions in 2005 in the transport sector of Busan were from the ships arriving in and departing from the port. The Korea Transport Institute (2009) reported that about $41 \%$ of total transportation-related GHG emissions in 2007 resulted from ships. The estimation results of these two past top-down studies showed a questionable difference in the GHG emissions because incongruous geographical areas and estimation methods were used in evaluating the GHG emissions inventory without taking into account GHG mitigation actions.

Consequently, it is very difficult for Busan to undertake MRV GHG mitigation actions utilizing the topdown GHG emissions from the past studies. Furthermore, no attempts have been made to estimate the GHG emissions from the port of Busan by accounting for port-related activities of the different transportation modes, such as vessel speed, vessel berthing time, and travel distance of on-road trucks and railroad locomotives. With these challenges in mind, this study estimates the first activity-based GHG emissions inventory of the port of Busan, studying the four transportation modes used in the port: marine vessels, cargohandling equipment, heavy-duty trucks, and railroad locomotives.

\section{ESTIMATING ACTIVITY-BASED GHG EMISSIONS}

Estimates of the activity-based GHG emissions 
according to transportation mode in the port of Busan were developed using numerous activity datasets obtained from the Busan Port Agency (BPA). Basically, the activity-based emissions were quantified by multiplying the Korean standard emission factors based on the 2006 IPCC guidelines by the activity data manipulated and reconstructed to use the latest estimation methodologies. In the next subsections, the estimation methods for each emission source are explained in detail.

\subsection{Marine Vessels}

In this study, the GHG emissions from marine vessels were estimated using the measureable port-related activities within the boundaries of Busan Port. Specifically, the port-related activities of the various types of marine vessels and their specifications were collected from the Port Management Information System (PORT-MIS), which tracks and records the movement of marine vessels entering and departing the port of Busan. Based on the estimation methods established by the National Institute of Environmental Research (2007), this study estimated the GHG emissions from marine vessels according to two types of ship operation: maneuvering (i.e., main engine emissions are dominant but at lower loads) and hotelling (i.e., the emissions from auxiliary engines dominate with the main engine off).

Eq. (1) represents the GHG emissions of marine vessels operating in maneuvering mode.

$$
E_{m}=\sum_{p=1}^{3} \sum_{i=1}^{n} m d_{i} \times f e_{i}^{-1} \times e f_{p},
$$

where $m d_{i}$ is the maneuvering distance of the $i$ th vessel $(\mathrm{km}), f e_{i}$ is the fuel economy of the $i$ th vessel (L/ $\mathrm{km}$ ) in gross tonnage, as shown in Table $1, n$ is the total number of vessels during the analysis period, and $e f_{p}$ is the emission factor for pollutant $p$ in which 1,2 , and 3 were coded for $\mathrm{CO}_{2}, \mathrm{~N}_{2} \mathrm{O}$, and $\mathrm{CH}_{4}$, respectively (see Table 2). The maneuvering distance of each vessel was estimated by measuring the roundtrip distance between the berthing terminal and the boundary of Busan Port on the electronic navigational chart.

For estimating the GHG emissions in hotelling, Eq. (2) was used.

$$
E_{h}=\sum_{p=1}^{3} \sum_{i=1}^{n}\left(f c_{i} \times 0.2\right) \times 0.79 \times e f_{p},
$$

where $f c_{i}$ is the fuel consumption of the $i$ th vessel at full power(ton/day), the factor 0.2 is used to reflect that the hotelling fuel consumption is about $20 \%$ of the full power fuel consumption, the factor of 0.79 (day/vessel) is the average hotelling time of marine vessels in Korea, and the rest of the notations are as
Table 1. Fuel economy of marine vessels.

\begin{tabular}{rc}
\hline Gross tonnage $(\mathrm{GT})$ of the vessel & Fuel economy $(\mathrm{L} / \mathrm{km})$ \\
\hline $\mathrm{GT} \leq 100$ & 0.19 \\
$100<\mathrm{GT} \leq 1,000$ & 0.122 \\
$1,000<\mathrm{GT} \leq 10,000$ & 0.046 \\
$10,000<\mathrm{GT} \leq 20,000$ & 0.028 \\
$20,000<\mathrm{GT} \leq 50,000$ & 0.022 \\
$\mathrm{GT}>50,000$ & 0.01 \\
\hline
\end{tabular}

Source: National Institute of Environmental Research (2007)

Table 2. Emission factors for marine vessels.

\begin{tabular}{lccc}
\hline \multirow{2}{*}{ Pollutant } & \multicolumn{3}{c}{ Emission factor (kg/TJ) } \\
\cline { 2 - 4 } & Lower & Default & Upper \\
\hline $\mathrm{CO}_{2}$ & 72,600 & 74,100 & 74,800 \\
$\mathrm{~N}_{2} \mathrm{O}$ & 1.2 & 2 & 2.8 \\
$\mathrm{CH}_{4}$ & 3.5 & 7 & 10.5 \\
\hline
\end{tabular}

Source: IPCC (2006)

Table 3. Fuel consumption factors at full-power.

\begin{tabular}{lc}
\hline \multicolumn{1}{c}{ Ship type } & Consumption at full power (tone/day) \\
\hline Solid bulk & $20.186+0.00049 \times \mathrm{GT}$ \\
Liquid bulk & $14.865+0.00079 \times \mathrm{GT}$ \\
General cargo & $9.8197+0.00143 \times \mathrm{GT}$ \\
Container & $8.0552+0.00235 \times \mathrm{GT}$ \\
Ro-Ro/Cargo & $12.834+0.00156 \times \mathrm{GT}$ \\
Passenger & $16.904+0.00198 \times \mathrm{GT}$ \\
High-speed ferry & $39.483+0.00972 \times \mathrm{GT}$ \\
Inland cargo & $9.8197+0.00143 \times \mathrm{GT}$ \\
Sail ships & $0.4268+0.00100 \times \mathrm{GT}$ \\
Tugs & $5.6511+0.01048 \times \mathrm{GT}$ \\
Fishing & $1.9387+0.00091 \times \mathrm{GT}$ \\
Other ships & $9.7126+0.00091 \times \mathrm{GT}$ \\
All ships & $16.263+0.001 \times \mathrm{GT}$ \\
\hline
\end{tabular}

Source: IPCC (2006)

previously stated. Since any specific hotelling characteristics of the vessels whose arrival purposes were not directly related to freight and passenger loading and unloading were unknown, the hotelling GHG emissions were only estimated for the marine vessels whose arrival purpose was either freight/passenger loading or unloading.

The fuel consumption estimated as a function of gross tonnage, shown in Table 3, was used as a default value for each vessel. However, the hotelling GHG emissions of several vessels of unknown type (Table 3 ) were estimated using the fuel consumption factors for "All ships", as recommended by the National Institute of Environmental Research (2007). Finally, the total GHG emissions of marine vessels arriving in and departing from Busan Port were estimated simply by summing the maneuvering and hotelling emissions. 
Table 4. Energy consumption rates of CHE.

\begin{tabular}{lcc}
\hline CHE & Energy source & $\begin{array}{c}\text { Energy consumption } \\
(\mathrm{kWh} / \mathrm{TEU}, \mathrm{L} / \mathrm{TEU})\end{array}$ \\
\hline CC & Electricity & 3.63 \\
e-TC & Electricity & 1.67 \\
TC & Diesel & 1.04 \\
RS & Diesel & 0.65 \\
YT & Diesel & 0.46 \\
\hline
\end{tabular}

\section{2 Cargo Handling Equipments}

The cargo handling equipment (CHE) inventoried in this study consisted of container cranes (CC), transfer cranes (TC), reach stackers (RS), and yard tractors (YT), all of which are used for loading and/or discharging cargo on terminals in the port of Busan. Since each piece of cargo handling equipment has a different energy consumption rate for dealing with 1-TEU, the energy consumption rate for each piece of equipment at a terminal in Busan Port was examined in 2008.

Table 4 represents the energy consumption rates for each CHE obtained from the one-year sample dataset on a container terminal in the port of Busan; these rates are very similar to those examined in the port of Gwangyang (Kim et al., 2007). Consequently, the GHG emissions of CHE were estimated using Eq. (3).

$$
E_{C H E}=\sum_{p=1}^{3} \sum_{t=1}^{T} \sum_{i=1}^{n} e c_{j} \times C H E_{t j} \times T E U_{t} \times e f_{p},
$$

where $e c_{j}$ is the energy consumption of the $j$ th CHE in dealing with 1-TEU, $C H E_{t j}$ is the number of the $j$ th CHE operated in terminal $t, T E U_{t}$ is the total TEUs on terminal $t$, and the rest of the notations are as previously stated. When estimating the GHG emissions from the CC and electric transfer crane (e-TC), the estimated electricity consumption rates of the equipment were converted to "TJ" using the annual national electricity productions (For more information about the conversion and emission factors, see Yang et al., 2010).

\section{3 Heavy-Duty Trucks}

Unlike the marine vessels and CHE, the port-related activities of trucks have not been systematically maintained by BPA. Thus, the travel demand model was employed to estimate the truck activities represented as the vehicle kilometers traveled(VKT), as in a previous study (Starcrest Consulting Group, 2007). The estimation procedure for obtaining GHG emissions of heavy-duty trucks is illustrated in Fig. 1.

Specifically, the activities of trucks that traveled to the port of Busan were estimated using the Korea Transport Database (KTDB) disseminated by the Korea Transport Institute (2005). The KTDB consists of the number of trips between the specified 659 traffic ana-

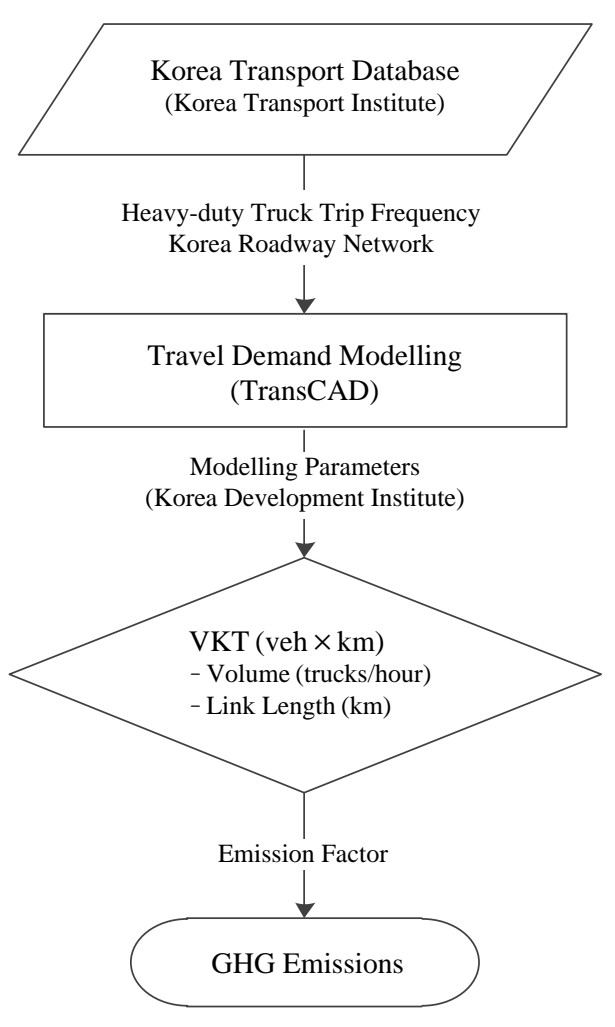

Fig. 1. Estimation procedure for heavy-duty trucks.

lysis zones (TAZs) in the Busan metropolitan area and the associated roadway networks. To estimate the emissions from trucks that traveled to the port of Busan, the trip frequencies of trucks between TAZs containing terminals in the port of Busan were extracted using the guidelines provided by the Korea Development Institute (2008).

Using the manipulated truck trip frequencies and roadway network as the input dataset in the travel demand model, this study estimated the vehicle kilometers traveled(VKT) of the trucks within the analysis boundaries. The VKTs of the trucks can be reported as the output of the travel demand model. Due to the lack of truck activity data on terminals, this study exclusively analyzed the truck emissions using the onroad activities consisting of travel on public roadways outside the boundaries of Busan Port but within the boundaries of the Busan metropolis. Relevant references providing greater detail on the travel demand model are available (e.g., Ortuzar \& Willumsen, 2001; Korea Development Institute, 2008).

The modeling results show that the trucks transporting cargo to and from the port of Busan generally travel via expressway. Specifically, more than $30 \%$ of the container truck trips travel on urban highways, such as Beonyeong Road and Dong-seo Road, con- 
Table 5. An example of truck activity modeling results.

\begin{tabular}{cccccc}
\hline & \multirow{2}{*}{$\begin{array}{c}\text { Length } \\
(\mathrm{km})\end{array}$} & $\begin{array}{c}\text { Average } \\
\text { speed } \\
(\mathrm{kph})\end{array}$ & \multicolumn{3}{c}{ Traffic volume (veh/day) } \\
\cline { 4 - 6 } & & $\begin{array}{c}\text { Passenger } \\
\text { car }\end{array}$ & Bus & Truck \\
\hline 1 & 2.5 & 35 & 20400 & 532 & 1543 \\
2 & 1.2 & 60 & 10253 & 241 & 435 \\
$\ldots$ & $\ldots$ & $\ldots$ & $\ldots$ & $\ldots$ & $\ldots$ \\
1251 & 0.8 & 62 & 10254 & 126 & 1284 \\
1252 & 3.5 & 90 & 13265 & 127 & 624 \\
\hline
\end{tabular}

necting several terminals in the port of Busan and Expressway No. 1 and Expressway No. 10, respectively.

Table 5 shows a brief example of the travel demand model results containing the truck traffic volumes and speeds on the roadways in the boundary of Busan. Using this result, the VKT of the trucks for each roadway section (vehicle $\cdot$ kilometers/day) can be easily calculated by multiplying the truck traffic volume by the roadway length. For example, the truck-VKT for link ID 1 can be estimated as 3,858 trucks - kilometers/day (i.e., $2.5 \times 1543$ ).

To estimate the GHG emissions from the trucks transporting cargo to or from the port of Busan, Eq. (4) was used.

$$
E_{H D T}=\sum_{p=1}^{3} \sum_{i=1}^{n} T V_{i} \times L_{i} \times 365 \times e f_{p},
$$

where $T V_{i}$ is the truck volume assigned on the $i$ th roadway segment (trucks/day), $L_{i}$ is the length of the $i$ th roadway segment within the boundary of Busan, and $e f_{p}$ is the emission factor for pollutant $p$ when the travel speed is about $50 \mathrm{kph}$. To take into account the uncertainty of the emission factor, the lower and upper emission factors were estimated using the emission factor function developed by the Motor Vehicle Emission Research Laboratory (2001). Specifically, the lower and upper emission factors were estimated using the travel speeds $40 \mathrm{kph}$ and $50 \mathrm{kph}$, respectively (see Table 6).

\section{4 Railroad Locomotives}

To estimate the activity-based emissions of the railroad locomotives in the port of Busan, the total amount of TEUs transported by railroad locomotives arriving in and departing from the port of Busan from 2000 to 2007 were collected based on the data of the Korea Railroad Corporation. The statistics show that 3,046,670 TEUs were transported through 1,433,459 railroad cars from two railroad stations in the port of Busan (Busanjin and Sinseondae) to 34 other stations during the analysis period.

The emissions from railroad locomotives were estimated based on the on-railroad activities within the
Table 6. Emission factors for heavy-duty trucks.

\begin{tabular}{lccc}
\hline \multirow{2}{*}{ Pollutant } & \multicolumn{3}{c}{ Emission factor $(\mathrm{g} / \mathrm{veh} \cdot \mathrm{km})$} \\
\cline { 2 - 4 } & Lower & Default & Upper \\
\hline $\mathrm{CO}_{2}$ & 1,301 & 1,388 & 1,520 \\
$\mathrm{~N}_{2} \mathrm{O}$ & 0.03 & 0.04 & 0.04 \\
$\mathrm{CH}_{4}$ & 0.06 & 0.08 & 0.09 \\
\hline
\end{tabular}

Source: Cheong et al. (2007), Motor Vehicle Emission Research Laboratory (2001)

Table 7. Fuel consumptions of diesel-powered trains.

\begin{tabular}{cc}
\hline Year & Fuel consumption $(\mathrm{L} / \mathrm{car} \cdot 100 \mathrm{~km})$ \\
\hline 2000 & 20.29 \\
2001 & 23.06 \\
2002 & 22.72 \\
2003 & 23.11 \\
2004 & N/A \\
2005 & 22.49 \\
2006 & 22.08 \\
\hline
\end{tabular}

Source: Korea Railroad Corporation (2000-2006)

Table 8. Emission factors for diesel-powered trains.

\begin{tabular}{lccc}
\hline \multirow{2}{*}{ Pollutant } & \multicolumn{3}{c}{ Emission factor (kg/TJ) } \\
\cline { 2 - 4 } & Lower & Default & Upper \\
\hline $\mathrm{CO}_{2}$ & 72,600 & 74,100 & 74,800 \\
$\mathrm{~N}_{2} \mathrm{O}$ & 1.67 & 4.15 & 10.4 \\
$\mathrm{CH}_{4}$ & 14.3 & 28.6 & 85.8 \\
\hline
\end{tabular}

Source: IPCC (2006)

metropolitan boundaries of Busan using Eq. (5).

$$
E_{R L}=\sum_{p=1}^{3} \sum_{i=1}^{2} C K T_{i} \times f e_{C K T} \times e f_{p},
$$

where $C K T_{i}$ is the car kilometers traveled (car-100 km) from the $i$ th station in the port of Busan, $f e_{C K T}$ is the fuel economy (L/car-100 km), as summarized in Table 7 , and $e f_{p}$ is the emission factor (see Table 8).

To obtain the CKT activities, the total number of cars in each train arriving in and departing from $\mathrm{Bu}-$ sanjin and Sinseondae stations in the port of Busan were multiplied by the travel distance within the boundaries of Busan from the two stations to the other 34 stations, distances which ranged from $22 \mathrm{~km}$ to $53 \mathrm{~km}$.

\section{ESTIMATION RESULTS}

This section provides the GHG emissions from the four transportation modes in the port of Busan from 2000 to 2007, which were estimated using the methodologies described in the previous section. Table 9 
Table 9. GHG emissions in Busan port $\left(\mathrm{GgCO}_{2}\right.$-eq).

\begin{tabular}{|c|c|c|c|c|c|c|c|c|c|c|c|c|}
\hline \multirow{2}{*}{ Year } & \multicolumn{3}{|c|}{ Marine vessels } & \multicolumn{3}{|c|}{ Cargo handling equipment } & \multicolumn{3}{|c|}{ Heavy-duty trucks } & \multicolumn{3}{|c|}{ Railroad locomotives } \\
\hline & Lower & Default & Upper & Lower & Default & Upper & Lower & Default & Upper & Lower & Default & Upper \\
\hline 2000 & 387.80 & 396.36 & 401.65 & 55.87 & 57.69 & 60.62 & 100.96 & 103.01 & 109.55 & 4.18 & 4.43 & 5.85 \\
\hline 2001 & 410.69 & 419.75 & 425.35 & 83.09 & 85.72 & 89.80 & 109.55 & 135.46 & 118.40 & 4.41 & 4.69 & 6.08 \\
\hline 2002 & 472.33 & 482.76 & 489.20 & 94.40 & 97.26 & 101.45 & 124.49 & 150.41 & 133.78 & 4.45 & 4.74 & 6.13 \\
\hline 2003 & 512.21 & 523.51 & 530.50 & 109.45 & 112.70 & 117.29 & 133.70 & 169.94 & 143.27 & 4.81 & 5.15 & 6.49 \\
\hline 2004 & 510.27 & 521.53 & 528.49 & 128.82 & 133.30 & 138.46 & 192.54 & 195.22 & 206.95 & 4.77 & 5.10 & 6.46 \\
\hline 2005 & 538.56 & 550.45 & 557.80 & 130.96 & 135.50 & 140.72 & 193.91 & 197.04 & 208.37 & 5.09 & 5.47 & 6.78 \\
\hline 2006 & 549.61 & 561.74 & 569.24 & 138.88 & 143.60 & 148.92 & 204.25 & 208.77 & 219.02 & 5.38 & 5.80 & 7.09 \\
\hline 2007 & 599.27 & 612.50 & 620.67 & 147.72 & 152.60 & 157.96 & 219.76 & 224.90 & 235.00 & 5.27 & 5.68 & 6.97 \\
\hline Mean & 497.59 & 508.58 & 515.36 & 111.15 & 114.80 & 119.40 & 159.90 & 173.09 & 171.79 & 4.80 & 5.13 & 6.48 \\
\hline
\end{tabular}

shows the GHG emissions during the analysis period represented as the comparable $\mathrm{CO}_{2}$ equivalents $\left(\mathrm{CO}_{2^{-}}\right.$ eq), which were obtained by multiplying the mass and the 1996 IPCC global warming potentials of carbon dioxide, methane, and nitrous oxide: $\mathrm{CO}_{2}=1, \mathrm{CH}_{4}=$ $21, \mathrm{~N}_{2} \mathrm{O}=310$ (IPCC, 1995).

From 2000 to 2007, the average total Busan Port GHG emissions from the four transportation modes were $6,413 \mathrm{Gg} \mathrm{CO}_{2}$-eq, ranging from $6,188 \mathrm{Gg} \mathrm{CO}_{2}$-eq to $6,504 \mathrm{Gg} \mathrm{CO}_{2}$-eq, as shown in Table 9. The average annual GHG emission was $802 \mathrm{Gg} \mathrm{CO}_{2}$-eq, with an upper value of $813 \mathrm{Gg} \mathrm{CO}_{2}$-eq and a lower value of $773 \mathrm{Gg} \mathrm{CO}_{2}$-eq. Overall, the annual total GHG emissions from the port of Busan were positively associated with the annual cargo tonnage handled (i.e., the total weight of goods loaded and discharged in the port of Busan), as shown in Fig. $2\left(\mathrm{R}^{2}=0.98\right)$. Thus, it is possible to infer that the GHG emissions in the port of Busan can be appropriately explained by the cargo tonnage handled. In other words, these statistics show that changes in transportation GHG emissions in the port of Busan primarily reflect variation in travel activity that accompanies year-to-year economic fluctuations.

Emissions increased by $12 \%$ from 2005 to 2007. This increase is primarily a result of an increase in the amount of cargo handled in Busan Port, which increased by about $13 \%$ during the same period. This result reflects the lack of GHG mitigation actions implemented in the port of Busan during this period.

Fig. 3 illustrates the average portion of the GHG emissions in the port of Busan for each of the transportation modes. About $63 \%$ of GHG emissions in the port of Busan resulted from "marine vessels", including full-container ships, semi-container ships, and passenger ships. "Cargo-handling equipment", which is used for loading and discharging of cargo in terminals, accounted for $14 \%$ of total GHG transportation emissions. "Heavy-duty trucks" accounted for $22 \%$ of total GHG transportation emissions, while "railroad

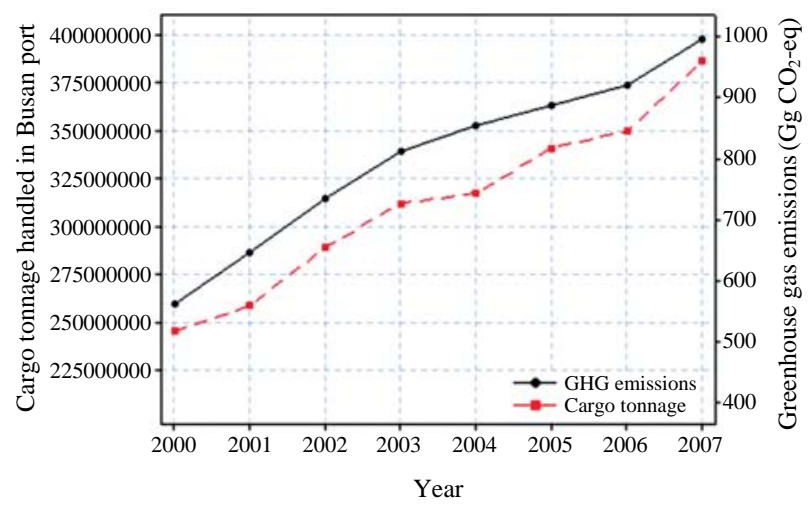

Fig. 2. GHG emissions and cargo tonnage (2000-2007).

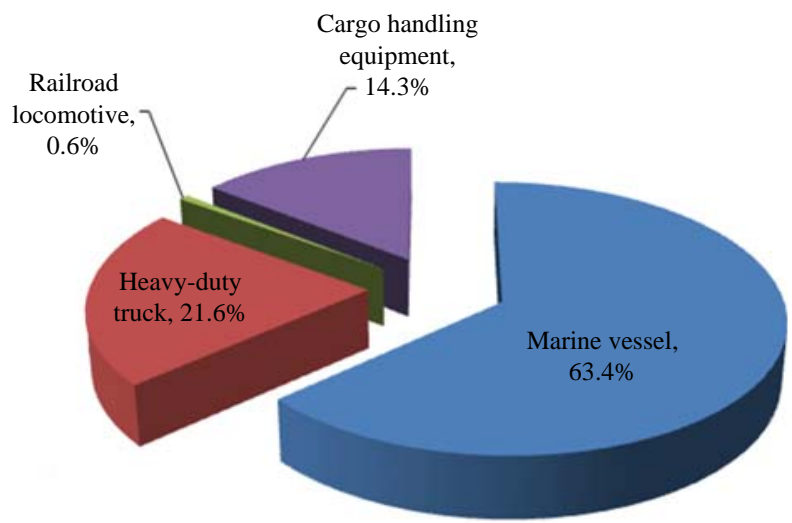

Fig. 3. GHG emissions of the four transportation modes.

locomotives" only accounted for less than $1 \%$ of total GHG transportation emissions in the port of Busan. It is noteworthy that the remarkably high magnitude of GHG emissions from "marine vessels" reflects the approximately $40 \%$ of all containers transported through Busan Port that are transferred to other ports without movement between ships or land vehicles, such as heavy-duty trucks or railroad locomotives. 


\section{CONCLUSIONS AND RECOMMENDATIONS}

This study provides the first activity-based GHG emission inventory of the port of Busan and its four transportation modes: marine vessels, cargo-handling equipment, heavy-duty trucks, and railroad locomotives. The key findings regarding the GHG emissions in the port of Busan using the most recent and complete activity data are as follows:

- The average annual transportation GHG emission in the port of Busan was $802 \mathrm{Gg} \mathrm{CO}_{2}$-eq.

- The increase in the transportation GHG emissions in the port of Busan during the analysis period can be systematically explained by the amount of cargo handled $\left(\mathrm{R}^{2}=0.98\right)$.

- About $64 \%$ of the total GHG emissions in the port of Busan were from marine vessels because more than $40 \%$ of all maritime containerized trade flows in the port were transshipment traffic.

- Approximately $22 \%$ of the total GHG emissions in the port of Busan were from on-road or railroad vehicles, which transport cargo to or from the port of Busan.

- The remaining $14 \%$ of the total GHG emissions were due to cargo handling equipment, such as cranes, yard tractors, and reach stackers.

This study provides the first activity-based GHG emissions according to transportation mode in the port of Busan, and further study should be undertaken to include the idling emissions of the heavy-duty trucks and railroad locomotives in the port. In addition, the hotelling (idling) emissions of marine vessels should be carefully estimated by examining the hotelling time of each vessel. The issues resulting from idling emissions clearly resulted from the lack of idling-related activities of the four transportation modes in the port of Busan. Hence, it is highly recommended that the BPA collect and maintain data on idling-related activities, such as the hotelling times of marine vessels, switching operation times of locomotives, and on-terminal times of heavy-duty trucks. Future calculations of transportation GHE emissions using these idling activities should provide further insight into the magnitudes of these emissions and the factors affecting them.

Although it is anticipated that the analysis is sufficient to provide the total amount of GHG emissions of four transportation modes in the port of Busan, the results should be interpreted with caution because this study was based on the current activity database, which should be improved for more detailed study. A more comprehensive analysis including idling activities and more suitable emission factors will yield more reliable results.

\section{ACKNOWLEDGEMENTS}

This work was supported by the South Korean Ministry of Environment (the graduate program specializing in climate change).

\section{REFERENCES}

American Association of Port Authorities (2008) AAPA World Port Rankings 2008.

Cheong, J., Kim, H., Lee, S.M., Lee, S.H., Jang, Y. (2007) Greenhouse Gas Emissions Inventory in Busan Metropolitan City, Kyungsung University.

IPCC (1995) IPCC Second Assessment Climate Change 1995, Intergovernmental Panel on Climate Change.

IPCC (2006) 2006 IPCC Guidelines for National Greenhouse Gas Inventories, National Greenhouse Gas Inventories Program, Japan.

Kim, W., Choi, S., Ha, T. (2007) A Study on an Energy Cost-saving Plan for Container Terminals, Korea Maritime Institute.

Korea Development Institute (2008) Manual on Pre-Feasibility Analysis of Road and Railroad Studies.

Korea Maritime Institute (2006) Survey on Origin and Destination for Import and Export Freights in Korea, Korea Transport Institute.

Korea Railroad Corporation (2000-2006) Korea Railroad Statistical Yearbook.

Korea Transport Institute (2005) Origin-Destination Travel Data in Korea.

Korea Transport Institute (2009) Survey on Greenhouse Gas Emissions and Energy Consumption.

Motor Vehicle Emission Research Laboratory (2001) An Investigation of Green House Gas Emission From Automobiles, National Institute of Environmental Research.

National Institute of Environmental Research (2007) Manual of Estimation Methods of Air Pollutants, Ministry of Environment.

Ortuzar, J.d.d., Willumsen, L.G. (2001) Modelling Transport, John Wiley \& Sons, LTD, New York.

Starcrest Consulting Group (2007) Port of Los Angeles Inventory of Air Emissions.

Yang, J., Lee, W., Huh, Y., Kim, Y., Jang, Y., Cheong, J., Shin, K. (2010) A Study on Greenhouse Gas Mitigation Actions in the Port of Busan, Busan Development Institute.

(Received 5 October 2010, accepted 26 January 2011) 